required in different azimuths to ascertain that we are dealing with a single circular disc, and not with two neighbouring discs, as in the case of Capella. The resulting angular diameter is $0.045^{\prime \prime}$; Prof. Eddington had predicted $0.05 \mathrm{I}^{\prime \prime}$ from the visual magnitude and assumed surface brightness, and Prof. Seeliger deduced $0.042^{\prime \prime}$ in a somewhat similar manner. The linear diameter found (about 300 times that of the sun) depends on the assumed parallax, which, unfortunately, is decidedly uncertain; further determinations seem urgently to be called for. Prof. Lindemann pointed out the extraordinarily low density that such a diameter implies if we assume that the mass is of the order of twenty-five times that of the sun.

Other stars for which a diameter determination is hopeful are Antares and Aldebaran, and possibly Arcturus. Sirius and Vega will doubtless be attempted, but with less prospect of success.

A. C. D. C.

\title{
Culture and Environment in the Cameroons.
}

$\mathrm{FEW}$ areas in the African continent present problems of greater interest to the anthropologist than the Cameroons. Although the Germans produced a considerable amount of literature relating to the area while it was under their rule, there is still a great deal of work to be done before the complex ethnology of the country is elucidated. Capt. L. W. G. Malcolm, who saw service in the Cameroons during the war, is preparing a monograph which will be one of the first-fruits of our occupation. At a recent meeting of the Royal Anthropological Institute he gave a preliminary account of certain questions connected with the distribution of types of culture and its relation with the geographical environment.

In the Cameroons there are three main racial stocks, namely, the Bantu-speaking tribes, the Sudanese, and the Pygmies. Subsidiary immigrant races occupy certain areas in the north-east. Between the Bantu-speaking tribes and the Sudanese there are a number of tribes, some of which do not speak Bantu languages, and there is a distinct boundary between the Bantu-speaking and Sudanese races which is determined solely by the geographical nature of the country.

The material culture of the grassland area reveals the fact that the problem is of a most complex character. When dealing with tribes of mixed affinities it is extremely difficult to determine the various strata. Not only is there a local mixing of the tribes, but there are also various elements which have been brought in by invading tribes. This is partisularly the case in Bagam, where the tribe has been in- fluenced particularly from Bamum, in the north-east, while from Babanki, in the north, various forms of iron weapons have been introduced. The Balis have introduced among the grassland tribes the sleeveless gowns worn by the men. After Hausa and Fulani elements and the influence of the forest-beit tribes have been eliminated, it would appear that the chief characteristics of the grassland culture are weapons of copper, iron, and brass; socketed spearheads; a simple bow made from raphia palm, with a flat bowstring; arrows with wooden points; shields, either plaited or reinforced with wood; wooden slit-gongs; drums with skin tympana and wooden tautening wedges; flanged iron bells; iron-working (smelting and smithing); brass castings (Bagam and Bamum); pottery (coiled in the north-east); jutan cloth and woven fibre; decorative art with triangles and zigzags; cicatrisation; filing or chipping of the incisors; smoking pipes of metal and clay; animal and ancestral cults; and the use of carved masks and images. One of the most obvious and striking peculiarities of the grassland culture, however, is the quadrangular hut, with pyramidal or conical roof, ranged in streets, which differs distinctively from the forest-belt hut standing in its own irregularly placed clearing.

Capt. Malcolm's careful analysis of the culture of one area only of the Cameroons, even in this preliminary form, was not merely an indication of the extremely interesting material which still awaits investigation; it was also a valuable object-lesson of the method of studying a backward population which should form the essential basis of our administration in this and similar areas.

\section{The Science Masters' Association.}

$A^{T}$ the invitation of the Board of the Faculty of Natural Science, the annual meeting of the Science Masters' Association was held in Oxford on January $4-7$. About two hundred members attended, and by the kindness of the Master of Balliol and the President of Trinity they were housed in these two colleges.

The meeting began on the evening of January 4 with the address of the president (Mr. A. Vassall, of Harrow) on "Some Aspects of Science and Education." Mr. Vassall dealt with education in science from the preparatory school to the university, and showed the evils of teaching in the earlier stages as if all the boys were ultimately to become specialists. The teaching should be such as to give every boy an opportunity of realising the scope and aims of science. It should impart to every boy the understanding of scientific problems necessary for the equipment of a modern State, and not be merely a training for future work in science, which in many cases will never be taken up seriously.

A lecture on spectroscopy, given by Prof. T. R. No. 2673 , VOL. IO6]
Merton, was concerned largely with the part played by observation and technique; observation cannot be effective with faulty apparatus. In the spectroscopy of gases the influence of traces of impurities is very great, and many beautiful experiments were shown to illustrate the methods of dealing with them. The conditions under which nitrogen gives a band spectrum and a line spectrum were shown; a tube was exhausted and filled with helium sufficiently free to enable the conditions for obtaining either a band spectrum or a line spectrum to be demonstrated. Also, a striking experiment was shown by which the presence of neon in the atmosphere was made evident. The method of getting hydrogen into and out of tubes by means of a heated side-tube of palladium was illustrated, and the curious fluorescence of parts of the human body was shown by illuminating the audience by light of wave-length about $3660 \AA$.U., obtained by using a quartz mercury vapour lamp and a screen of special glass devised by Prof. R. W. Wood.

There were demonstrations in the various University laboratories, illustrating much of the teaching 
work of the University and some of the current investigations. Demonstrations were also given of the use of the microscope for the study of crystallisation, by Mr. T. V. Barker, who had prepared a pamphlet outlining a course of study suitable for schools, and of glass-blowing by Mr. B. Lambert, who gave many valuable hints on dealing with operations which are constantly a source of difficulty in making apparatus. All these demonstrations were repeated next day, and the association is greatly indebted to the distinguished University teachers who expended so much time and care on them.

A lecture on the control of growth was given by Mr. J. S. Huxley. After explaining the characteristics of the life-cycle of all animals, the lecturer showed how the growing stage could be accelerated or retarded by external conditions in the case of some lower organisms, and illustrated cases where it can be reversed. Two opposing processes may be distinguished, and by stimulating one or the other the progress of the resultant change can be controlled. An interesting case was related of an Australian soldier whose mind, as the result of shell-shock, reverted to the infantile stage, but, happily, on his return to Australia it developed again to the normal condition. Mr. Huxley went on to describe experiments with mice, the average life of which had been extended about 20 per cent. beyond the normal duration, and the treatment of a rat which had its youth restored after reaching a state of marked senility. In conclusion, the opinion was expressed that in the course of time it would be possible to extend the duration of man's life very appreciably.

A lecture on indicators and the law of mass action was delivered by Brig.-Gen. Hartley. The lecturer pointed out and illustrated the confusion resulting from the idea of neutralisation, and showed that the way to obtain a clear insight was to regard the indicators as weak acids or bases (fortunately the tautomeric changes need not be considered here) and work quantitatively in terms of the hydrion concentration from the known dissociation constants. Brig Gen. Hartley illustrated this by making four sets of solutions in which the hydrion concentration varied by factors of Io from $10^{-3}$ to $\mathrm{IO}^{-10}$ (made by adding to $N /$ io acetic acid the calculated amounts of a solution of sodium acetate, as by this method the accidental introduction of impurities does not seriously alter the hydrion concentration), and adding to all the members of each series methyl-orange, methylred, phenolphthalein, and litmus respectively. It was then evident between what limits of concentration the colour change occurs in each case. Graphs were made showing the resultant hydrion concentration when various amounts of a particular alkali were added to 25 c.c. of a given acid. From these graphs it was at once evident what would be a suitable indicator and how sharp the colour change would be. Some further graphs showed the immense difference that would result if the constant for water were to have a different value.

In a lecture on the Hedjaz Mr. D. Gr. Hogarth gave an account of the geographical conditions and a most interesting review of the political positions since rgr4 and their bearing on the war in the East.

Throughout the meeting there was an exhibition of apparatus and books by manufacturers and publishers.

\section{Research on the Pink Boll-worm.}

THE pink boll-worm, the larval stage of the 1 Tineinid moth, Gelechia gossypiella, Saunders, is responsible for considerable damage to cotton in most cotton-growing regions, and its importance in Egypt has led to an extensive study of its habits and of methods of control (H. A. Ballou, r920, "The Pink Boll-worm," Report of Ministry of Agriculture, Egypt; L. H. Gough, I9I9, "On the Effect Produced by the Attacks of the Pink Boll-worm on the Yield of Cotton-seed and Lint in Egypt," Agricultural Journal of Egypt, vol. ix.).

The pink boll-worm was first discovered in Egypt in 1910 , probably having been introduced in cotton from India, and in 1912 it had attained a position of first importance as a pest of cotton in that country, and since that time it has been the principal pest of this crop.

In its adult state Gelechia gossypiella is a small moth with a wing-spread of between ${ }_{5}$ and $19 \mathrm{~mm}$. The general colour of fresh specimens is copperybrown with blackish spots varying in size and intensity. The eggs are laid on the green parts of the cotton plant, and the larvæ make their way to a boll or bud, where they feed inside the developing seeds or upon the ovules. When fully grown, the larva measures ro to $12 \mathrm{~mm}$. in length, the pinkish colour occurring in broad transverse bars on a yellow ground, and may pupate in the boll or seed or enter the earth. The larval state lasts from ten to nineteen days, but late in the season the larva, instead of pupating when full grown, may enter a resting stage, in which it may remain for as long as thirty months. This is the most important stage in the life of the insect, and the principal effort at control is directed at the larvæ before and during this stage.

$$
\text { NO. } 2673 \text {, VOL. IO6] }
$$

The pink boll-worm damages cotton-seed in the boll, and its attacks result in reduced and weakened lint and reduced seeds, which may be light in weight and of low germinating power.

Legislation has made it compulsory for all plants to be pulled, and the remaining bolls destroyed, by a certain date, which varies between December I5 $_{5}$ and January $I_{5}$ in different districts; it has enforced the provision of approved machines for treating all seed in the ginneries by heat or fumigation, and made it compulsory for all stores containing cottonseed to be screened from May to August to prevent the escape of adults.

The first campaign on a large scale against the pink boll-worm was carried out in 1916 , and aimed at the destruction of resting larvæ in the bolls left in the field after the crop had been gathered. The method which is recommended for the future is for the cotton sticks to be removed from the field before cleaning, taken to a central place, and there cleaned by drawing through a comb or rake, no sticks to be allowed into a village until all have been passed by an inspector as clean, and the unclean sticks destroyed.

The picking of the crop should be as early as possible, as the attack of the pink boll-worm is more severe late in the season, and also the later larvæ are more likely to pass into the resting stage by which the infestation of the following year is caused.

Treatment of cotton-seed by heat at a temperature of from $53^{\circ}$ to $73^{\circ} \mathrm{C}$. was found to be effective in destroying all resting-stage larvæ, while having little effect on the percentage of germination of the seed. 